\title{
Projecting climate change impacts on Mediterranean finfish production: a case study in Greece
}

\author{
Orestis Stavrakidis-Zachou $^{1,2}$ (D) $\cdot$ Konstadia Lika ${ }^{2} \cdot$ Panagiotis Anastasiadis $^{1} \cdot$ \\ Nikos Papandroulakis ${ }^{1}$
}

Received: 21 October 2020 / Accepted: 7 April 2021 /Published online: 29 April 2021

(C) The Author(s) 2021

\begin{abstract}
Finfish aquaculture in the Mediterranean Sea faces increasing challenges due to climate change, while potential adaptation requires a robust assessment of the arising threats and opportunities. This paper presents an approach developed to investigate effects of climate drivers on Greek aquaculture, a representative Mediterranean country with a leading role in the sector. Using a farm level approach, dynamic energy budget models for European seabass and meagre were developed, and environmental forcing was used to simulate changes in production and farm profitability under IPCC scenarios RCP45 and RCP85. The effects of temperature and extreme weather events at the individual and farm levels were considered along with that of husbandry parameters such as stocking timing, market size, and farm location (inshore, offshore) for nine regions. The simulations suggest that at the individual level, fish may benefit from warmer temperatures in the future in terms of growth, thus reaching commercial sizes faster, while the husbandry parameters may have as large an effect on growth as the projected shifts in climatic cues. However, this benefit will be largely offset by the adverse effects of extreme weather events at the population level. Such events will be more frequent in the future and, depending on the intensity one assigns to them, they could cause losses in biomass and farm profits that range from mild to detrimental for the industry. Overall, these results provide quantification of some of the potential threats for an important aquaculture sector while suggesting possibilities to benefit from emerging opportunities. Therefore, they could contribute to improving the sector's readiness for tackling important challenges in the future.
\end{abstract}

Keywords Climate change Extreme weather events $\cdot$ Aquaculture $\cdot$ European seabass $\cdot$ Meagre . Mediterranean

Orestis Stavrakidis-Zachou ostavrak@hcmr.gr

1 Institute of Marine Biology, Biotechnology and Aquaculture, Hellenic Centre for Marine Research, 71500 Heraklion, Crete, Greece

2 Department of Biology, University of Crete, 71003 Heraklion, Crete, Greece 


\section{Introduction}

Aquaculture is increasingly under pressure from climate change, and the severity of the threats and the urgency to act are reflected by the EU and global agenda which is heavily oriented towards climate change. In line with the objectives of Paris Agreement of the United Nations Framework Convention on Climate Change (UNFCCC), equal focus should be given in tackling the causes of climate change by reducing greenhouse emissions as well as in building climate resilience by mitigation and adaptation (Fankhauser 2017; Teske 2019). To accomplish the latter, the first step is to assess the vulnerability of the food production sector in question, be it poultry and cattle farming, cropping, hunting, fisheries, or aquaculture, and evaluate the potential effects of the arising threats. While this may be intuitive for land-based activities such as poultry farming where complete control over the production process is feasible, this is not the case for aquaculture due to the multifactorial nature of the production process and the complex interactions with environmental drivers. For instance, the majority of aquaculture production in Europe comes from marine species ( $>84 \%$ in 2016) (FEAP 2017) that are farmed in the sea under the prevailing environmental conditions which are, thus, largely outside human control. It is therefore urgent to build knowledge regarding aquaculture at the geographical regions that are the most vulnerable which in turns requires the development of appropriate methodological frameworks to evaluate the threats arising from climate change. One such region appears to be the Mediterranean Sea, since the peculiarities of its basin and the low water exchange with other oceanic masses allow for a high rate of temperature increase, thus rendering it one of the most heavily afflicted areas by climate change (Azzurro et al. 2019; Oliver et al. 2018).

Specifically, the Mediterranean finfish aquaculture comprises predominantly of marine cage farming, with European seabass (Dicentrarchus labrax) and gilthead seabream (Sparus aurata) being the most important species. The two species make up for $95 \%$ of the total production, while others such as meagre (Argyrosomus regius) and greater amberjack (Seriola dumerili) have also started to emerge. Greece is the main EU producer for E. seabass and gilthead seabream with the annual production exceeding 135,000 tons, thus accounting for $60 \%$ of the EU and $24 \%$ of the global supply (FGM 2019). Greek aquaculture is an industry of considerable national and international significance which comprises of 65 companies with 328 farms and a total invested capital of over 740 million $€$ (FGM 2019). Other countries such as Spain and Italy amount for a smaller, yet significant, portion of the European production, while Turkey is the major non-European producer, accounting for over one third of the global production (FEAP 2016). In this paper, we focus on Greece as a representative case study for the Mediterranean. Moreover, due to its dominant role as an established species, the E. seabass was selected as the primary species for the analysis, also because it is considered less resilient to chronic stress than gilthead seabream (Samaras et al. 2018). The meagre was also included in the study as an emerging species with high potential for the diversification of the Mediterranean sector.

The economic importance of Mediterranean aquaculture is evident, and potential climate change impacts on the sector and the dependent communities have long been identified (Brugère and De Young 2015; Collins et al. 2020; Rosa et al. 2012). Although the main farmed species have been extensively studied, significant knowledge gaps exist on how the different climate-related drivers may affect fish farming in the future which hinders our capacity to quantify and assess potential threats. Namely, the majority of research focuses on rising temperature as the major driver of environmental change, while other related drivers 
such acidification, eutrophication, HABs, extreme events, sea level rise, salinity, invasive species, and diseases remain less documented (Reid et al. 2019). While this may be justified due to temperature having the most prominent effects on fish biology (Crozier and Hendry 2013), it consequently follows that the confidence in modelling and assessing the effects of temperature on farmed species is larger than that of other drivers which may require a different evaluation approach. Nevertheless, significant knowledge gaps even for the most studied drivers exist (Reid et al. 2019).

Specifically regarding those gaps, temperature has been associated with changes in fish traits such as the age at maturity, the timing of reproduction, growth, survival, and fecundity (Crozier and Hendry 2013), and the underlying physiological and metabolic mechanisms have generally been understood. For established species like E. seabass in particular, the thermal preferences have been identified (Claireaux et al. 2006; Ozolina et al. 2016), while they remain elusive for emerging species such as the meagre. However, in both cases, the biological responses to prolonged exposure to extreme temperatures and quantification of the associated mortality rates at the edges of their temperature tolerance range have not been adequately studied despite an increasing interest in that direction (Islam et al. 2020; Kir et al. 2017; Ozolina et al. 2016). On the other hand, for acidification, which is the second most documented climate driver, elevated $\mathrm{CO}_{2}$ concentrations have been shown to induce only small physiological changes in fish (Francisco et al. 2015; Pope et al. 2014). With respect to other climate drivers, literature appears scarce. The assessment of HAB dynamics has been challenging and executed predominantly at a historical level and for a small number of areas (Spatharis et al. 2009; Wells et al. 2015) which renders our predictive capacity of such events in the Eastern Mediterranean basin rather poor. Similarly, the physiological responses to hypoxic stress for most commercial species have not been extensively studied (PérezJiménez et al. 2012), and only a handful of studies investigate the effects of salinity. Even fewer studies raise the topic of extreme events, with the available studies discussing the role of extreme events on infrastructure damage and escapees (Jackson et al. 2015). Finally, for the epidemiology of fish pathogens in the Mediterranean, significant knowledge gaps appear both on the biology and distribution patterns of the pathogens as well as the immunological responses of the farmed species. While research for individual climate change drivers is scarce, there is even more limited information on the combined effect of different drivers. Nevertheless, there has been significant progress in recent years to address those gaps with the development of tools such as the EcoWin and FARM models (https://www.longline.co.uk) and a recent review (Cascarano et al., submitted).

In this paper, we present an approach developed to investigate effects of climate drivers on the Mediterranean finfish aquaculture by simulating a range of scenarios for Greece, a representative Mediterranean country. The article presents work conducted within the Horizon 2020 ClimeFish project (https:/climefish.eu/mediterranean/) and is based on a modelling framework that allows simulation of future climate scenarios on aquaculture production while accounting for husbandry parameters that are relevant to the industry. The objective is to act as the first step of quantifying and assessing climate change impacts on the Mediterranean finfish aquaculture. This information may then be used to facilitate responsible and science-based decision making and eventually adaptation to climate change according to the agreed upon national and international goals. In addition to producing biological forecasting under various scenarios, the paper also discusses some economic extensions of the projected trends which allows for a more comprehensive assessment of potential impacts. Finally, given the knowledge gaps and limitations mentioned above, 
temperature is the main climate driver that is explicitly modelled. However, an indirect approach to incorporate an additional climate driver, that of extreme weather events, has also been developed and included in the analysis. The aim is to provide a more holistic, yet not exhaustive, representation of the complexities involved in forecasting the effects of climate change.

\section{Methods}

Effects of climate change on Greek aquaculture production were simulated by adopting a farm level approach, an approach that is increasingly used in aquaculture research (Besson et al. 2016; Cobo et al. 2019). The first step of the process was to develop individual-based bioenergetic models for the two target species, namely, E. seabass and meagre. The upscale of the bioenergetics model to the farm level accounts for inter-individual variability by subdividing the population in cohorts that differ in the values of specific parameters which lead to differences in individual sizes at a given time. Next, model farms were considered at representative for aquaculture regions throughout Greece. In each region, typical production cycles were simulated for a group of each species at the environmental conditions specific of that region. The environmental variables were projected under two Intergovernmental Panel for Climate Change (IPCC) emission scenarios from the fifth assessment report (IPCC 2013) for two representative concentration pathways (RCPs), the "most likely" RCP4.5 scenario and the "worst-case" RCP8.5 scenario (Lotze et al. 2018; Sarà et al. 2018; Van Vuuren et al. 2011). Finally, three time periods were simulated, representing short (2015-2025), mid (2025-2035), and long (2045-2055)-term climate projections.

\subsection{Dynamic energy budget models}

The first step in the modelling process was to develop models for the two species that could predict at the individual level variables of interest for aquaculture in relation to changes in environmental drivers. To quantify such variables, the dynamic energy budget (DEB) theory (Kooijman 2010) was used which offers a comprehensive theoretical framework to describe the bioenergetics of an individual throughout its life. DEB-based models are able to capture changes in easily measurable variables such as weight and length explicitly as a function of temperature and food availability and, thus, can be used to study relevant biological responses in relation to shifts in environmental conditions. For this reason, their use in fish research is becoming increasingly popular with applications also in the field of climate research (Monaco and McQuaid 2018; Sara et al., 2018; Stavrakidis-Zachou et al. 2019a; Talbot et al. 2019). The feeding rate of an individual of a given size is proportional to a measure $f$ of the food availability. The quantity $f$ (called the scaled functional response) is an increasing function of the ambient food density, which in general is a function of time, and takes values between 0 (reflecting starvation) and 1 (feeding ad libitum). It represents the feeding rate as a fraction of the maximum one of an individual of that size. Upon ingestion, energy is assimilated and can then be used by the organism to support fundamental processes such as development, growth, maintenance, and reproduction. The physiological rates that govern the flow of energy among those processes are explicitly dependent on body size and, in the case of fish, seawater temperature which in the DEB context is described by the Arrhenius relationship. Here, we use the extended formulation of 
the Arrhenius equation (Kooijman 2010; Stavrakidis-Zachou et al. 2019a) which includes the lower and upper thermal tolerance boundaries for the species and, thus, allows to quantify the decline of biological performance at temperatures above the optimal range. The details of the model are given in the Electronic Supplemental Material (ESM).

For the two species, DEB parameters for the average individual were estimated following the procedure described in Marques et al. (2019), using physiological, morphological, and life history information from published literature. Subsequently, the models were validated against production datasets regarding growth and feed consumption covering the 2006-2016 period. The datasets were obtained confidentially from representative farms (eight for E. seabass and three for meagre) from different regions. The temperature conditions at the farm sites were used to simulate growth and feed consumption and then compare model predictions with the farm observations, which yielded close match between them. The model and its validation for E. seabass have been presented in Stavrakidis-Zachou et al. (2019a), while for meagre, the estimated parameters and the validation are provided in the ESM. For all simulations, the functional response $f$ was kept constant at the value of 0.8 since the simulations with this value satisfactorily matched the validation data. This is also consistent with common aquaculture practices, since the majority of farmers provide feed close to satiation or apply a restricted feeding approach.

\subsection{The model farm}

In the present work, a model farm is a marine cage farm representative of the study area, where a number of E. seabass or meagre individuals are grown from fingerlings to market size according to the prevailing environmental conditions. Based on the annual production of fingerlings (450 million) and the number of farms operating in Greece (328), the capacity of the model farm was set at 1.5 million individuals (FGM 2019).

Model farms were considered in a total of nine regions (R1-R9) which roughly covered the geographical area of Greece between latitudes $34^{\circ}$ and $42^{\circ} \mathrm{N}$ and longitudes $19^{\circ}$ and $30^{\circ} \mathrm{E}$ (Fig. 1, left). The regions were selected with the rationale of covering the major centres of aquaculture activity in Greece, as well as representing a large range of the possible temperature profiles in the country by including regions at both ends of the latitudinal and longitudinal axes. The locations of the aquaculture farms currently in operation are seen in Fig. 1 (right).
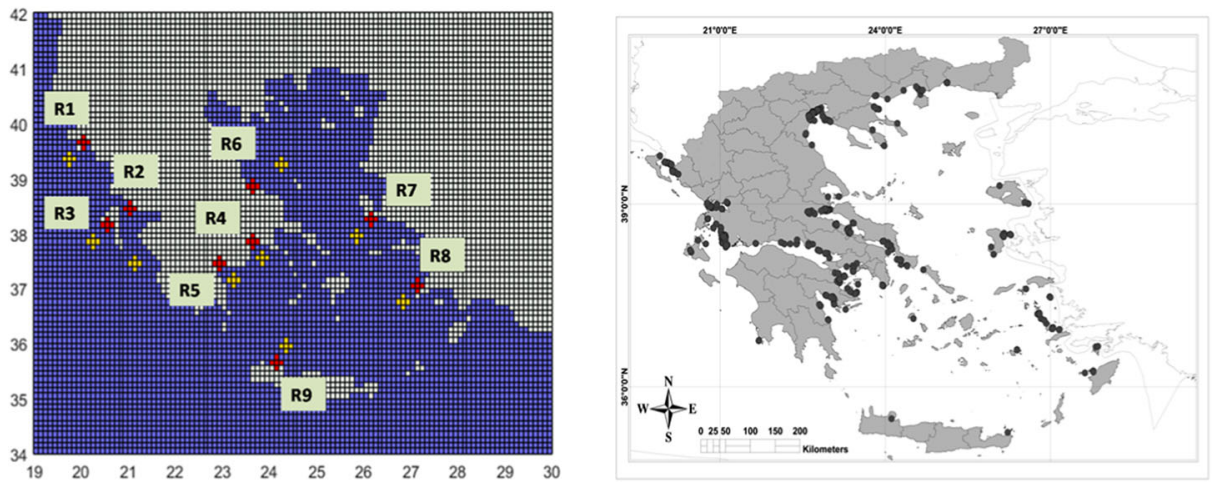

Fig. 1 Map of the simulated regions R1-R9 (left) and the location of operating Greek farms (right). Red colour denotes inshore and yellow offshore sites 
Moreover, two locations for farms were considered in each region, one inshore and one offshore based on their proximity to the coast. Given that the spatial resolution of the available downscaled climate projections was $10 \times 10 \mathrm{~km}$, inshore farms were delineated for grid cells located closest to the coast and offshore farms at least $30 \mathrm{~km}$ further into the sea. It must be highlighted that the offshore locations comprise an entirely hypothetical scenario for Greece, since at present, there are no offshore farms in operation. However, they have been included in the simulations in order to assess whether offshore farming offers potential for mitigation to climate change as it has been argued (Klinger et al. 2017).

In addition, in each farm, it was assumed that there are three potential periods for stocking, March, June, and September. This constitutes a slight extension of the common stocking period for those species which typically is spring and summer. The stocking period defines the temperature profile of a prospective production cycle and therefore determines potential species-specific positive and negative thermal windows for growth. While the stocking period does not constitute a climate driver but rather a managerial one, it has been included in our analysis to test for potential climate-induced shifts in the seasonality of growth that in turn may pinpoint to adaptation solutions.

Finally, the output of the model farm is biological as well as economic information. Apart from growth performance indicators (time to market size and feed consumption), the model predicts the total biomass produced for the group of fish if harvested at a specified, user defined, market size. Next, the profit from selling those fish is calculated based on the farm economic model, as described in Stavrakidis-Zachou et al. (2019b) which is also available in the ESM. Briefly, this model uses the predictions of the biological model in terms of biomass production and feed consumption to predict the farm profit by calculating the associated costs (labour, feeding, stocking, maintenance, depreciations, and interest) and subtracting them from the income generated by selling the fish.

\subsection{Simulations}

For each of the model farms (nine inshore and nine offshore) described above, a representative 3 -year production cycle was simulated. Simulations were performed for the two species (E. seabass and meagre), the three stocking months (March, June, and September), the two climate scenarios (RCP4.5 and RCP8.5), and the three time periods (short-, mid-, and long-term). For each simulation, the farm model for each species predicted the average times to reach two specified market sizes, the mean individual weight-at-time, the number of fish, the total biomass, the cumulative feed consumption, and the feed conversion ratio (FCR, as feed given over the weight gained) as well as the farm profit. Regarding the climate data forcing, they were downscaled projections $\left(10 \times 10 \mathrm{~km}^{2}\right)$ of daily sea surface temperature (SST) and wind velocity over the 2006-2055 period generated by the CERES project (https://ceresproject.eu/). Comparison of the SST projections during the 2006-2016 period with in situ measurements from farms and the Poseidon System (http://poseidon.hcmr.gr) showed tendency of the model to overestimate the winter minima and underestimate the summer maxima at inshore sites while it performed well at offshore sites. Therefore, SST data from farms at the nine regions during the reference period 2006-2016 were used to calibrate the projections at the inshore sites by implementing a "bias correction" (Falconer et al. 2019; Hawkins et al. 2013). Detailed description of the climate data, the "bias correction", as well as an illustration of the temperature differences across the different regions, climate scenarios, and projected periods are provided in the ESM. 
For the simulations, two sources of variability were considered, biological and environmental. Biological variability was introduced by subdividing the fish farm population for each species into a number of cohorts (not representing actual genetic cohorts) whose individual parameter values differed according to the covariation rules of DEB theory as described in Stavrakidis-Zachou et al. (2019a). Moreover, the cohorts also differed in terms of their stocking size. Briefly, it was assumed that certain DEB parameters associated with the physical design of the fish, namely, $\left\{\dot{p}_{A m}\right\}, E_{H}^{b}$, and $E_{H}^{p}$, covary interspecifically with the zoom factor (z), a parameter that relates to the mean maximum size of the individual. Therefore, by defining a factor $\zeta=z / z^{0}$, where $z^{0}$ is the zoom factor of the estimated ("reference") parameter values, the cohorts relate to the "reference" cohort as $\left\{\dot{p}_{A m}\right\}=\zeta\left\{\dot{p}^{0}{ }_{A m}\right\}, E_{H}^{b}=\zeta^{3} E_{H 0}^{b}$, and $E_{H}^{p}=\zeta^{3} E_{H 0}^{p}$. Each cohort was assigned a different $z$ value sampled randomly from a normal distribution with mean $z^{0}$ and standard deviation $\sigma$. For the simulations, we assume a constant coefficient of variation $c v$ of 0.1 , and thus $\sigma=c v \cdot z^{0}$, and set the number of cohorts at 50. As a result, individuals will differ among cohort in their assimilation and growth potential, resulting in different growth patterns. Environmental variability was introduced into the simulations via bootstrap sampling. For each of the three time periods, the 10-year daily SST and wind velocity datasets were used to generate bootstrap samples. The resampling was done by drawing with replacement random numbers between 1 and 10 and forming a number of triplets, each corresponding to a 3-year production cycle. The environmental variables of these samples were then forced into the model for each of the 50 cohorts. Preliminary simulations analysing the effect of environmental variability on fish growth revealed that it was negligible compared to the effect of the biological variability. For this reason, and in order to reduce computational time, 25 three-year bootstrap samples were used per cohort.

Apart from temperature affecting physiological rates, effort was given in incorporating the effect of additional environmental drivers. Namely, the effect of extreme weather events on the individual as well as the population level was considered. At the individual level, this was done by incorporating non-feeding days $(f=0)$ when wind velocity exceeded predefined thresholds (wind velocity $>45 \mathrm{~km} / \mathrm{h}$ ). The threshold, though subjective, was used to signify restricted farm accessibility or adverse weather conditions caused by high winds and waves which would hinder the feeding operations at the farm site. Furthermore, extreme events such as storms and heatwaves were modelled as effects at the population level that caused mortality, additionally to the expected one. The rationale is that storms can damage the cages and cause equipment failure, thus leading to escapee events, while prolonged high temperatures are tied to disease outbursts, both of which are incorporated as mortality losses in aquaculture terms. Therefore, by including extreme event induced mortality, the dynamics of the number of individuals in a farm is given by

$$
\frac{d N}{d t}=-\left(\mu+\mu_{T}+\mu_{S}\right) N
$$

where $N$ is the number of fish; $\mu$ is a background, size-dependent mortality; and $\mu_{T}$ and $\mu_{S}$ are the mortality rates related with extreme events such as high temperature (e.g. diseases) and storms (e.g. escapes). Both $\mu_{T}$ and $\mu_{S}$ are null for the majority of the production cycle, except for the days that extreme events occur. Here, we define a "heatwave" occurring when temperature exceeds $28^{\circ} \mathrm{C}$ for more than 4 days in a given week and a "storm" when wind velocity exceeds the wind threshold $(45 \mathrm{~km} / \mathrm{h})$ for four consecutive days. These thresholds, while subjective, are based on empirical knowledge as communicated by aquaculture 
producers. For instance, higher frequency of disease outbreaks is reported during the summer months when SST in Greece may reach values as high as $28-29^{\circ} \mathrm{C}$, while experimental work on E. seabass and meagre pinpoints to critical thresholds for survivability beyond $30{ }^{\circ} \mathrm{C}$ (manuscript in preparation). Furthermore, average wind speeds above $45 \mathrm{~km} / \mathrm{h}$ are disruptive for feeding and maintenance farm operations, while the wind gusts and wave heights associated with prolonged exposure to these conditions translate to significant operational and safety hazards (Yang et al. 2020). For simplicity, we assume that the mortalities caused by extreme events operate instantaneously at the end of the event.

\subsubsection{Effects at the individual level}

As a proxy for detecting trends at the individual level, we here discuss the production time needed to reach common market sizes (400 $\mathrm{g}$ and $800 \mathrm{~g}$ for E. seabass and $800 \mathrm{~g}$ and $1600 \mathrm{~g}$ for meagre) and the FCR. Moreover, to enable comparisons across scenarios and further analyse the trends, changes in the time to market size $(800 \mathrm{~g})$ for both species in the mid- and long-run are also illustrated as relative to short-term (i.e. present). Specifically, this is calculated as

$$
\text { relative difference }(\%)=\frac{\text { future-present }}{\text { present }} 100 \text {. }
$$

\subsubsection{Effects at the farm level}

On a farm level, the variables discussed are the biomass produced and the generated profit. Because the number of potential production scenarios are endless, we will here present a specific one. Specifically, a scenario was constructed with fixed production and economic parameters and was then simulated on all regions and climate scenarios. This was done to assess spatiotemporal shifts under different climate scenarios with focus on biological rather than economic changes. For this example, we assume that every model farm stocks 200,000 individuals at each one of the stocking periods and harvests them once they reach $800 \mathrm{~g}$ and farm profits are then calculated using the default economic model values for the various costs and prices. The analysis was done both for E. seabass and meagre. Considering that the focus of this exercise is the biological rather than the economic effects along with the fact that offshore farming has not yet been established in the region and, therefore, economic data for such farms do not exist, we have here applied the same default economic values (obtained in collaboration with the Federation of Greek Maricultures, see also Table S4, ESM) on both inshore and offshore farms.

However, biomass and profit are closely correlated with the severity of extreme events one assigns to them. Therefore, we additionally extend this example by formulating three extreme events scenarios that were also simulated on each model farm in order to investigate the severity of extreme weather events according to their type on a what-if scenario basis. These scenarios were termed "mild extreme events", "intense heatwaves", and "intense storminess". The first considers a mild intensity for both heatwaves and storms where each event causes $1 \%$ mortality to the growing population each time it occurs $\left(\mu_{T}=\mu_{S}=0.01\right)$, while the other two postulate a fivefold increase in the severity of heatwaves $\left(\mu_{T}=0.05, \mu_{S}=0.01\right)$ and storms $\left(\mu_{T}=0.01, \mu_{S}=0.05\right)$ respectively. It is important to highlight that in the absence of such data from farms, these mortality rates are hypothetical and based on the assumption that current technology without any adaptation is also applied in future projections. Therefore, potential adaptations of the industry that may reduce the impact of extreme events in the future are not considered. 


\section{Results}

\subsection{Effects at the individual level}

Both the environmental and managerial drivers considered in the analysis have a notable effect over time on an individual fish. The biological forecasting for all climate scenarios, time periods, and managerial drivers is summarized in Fig. 2a for E. seabass and Fig. 2b for meagre.
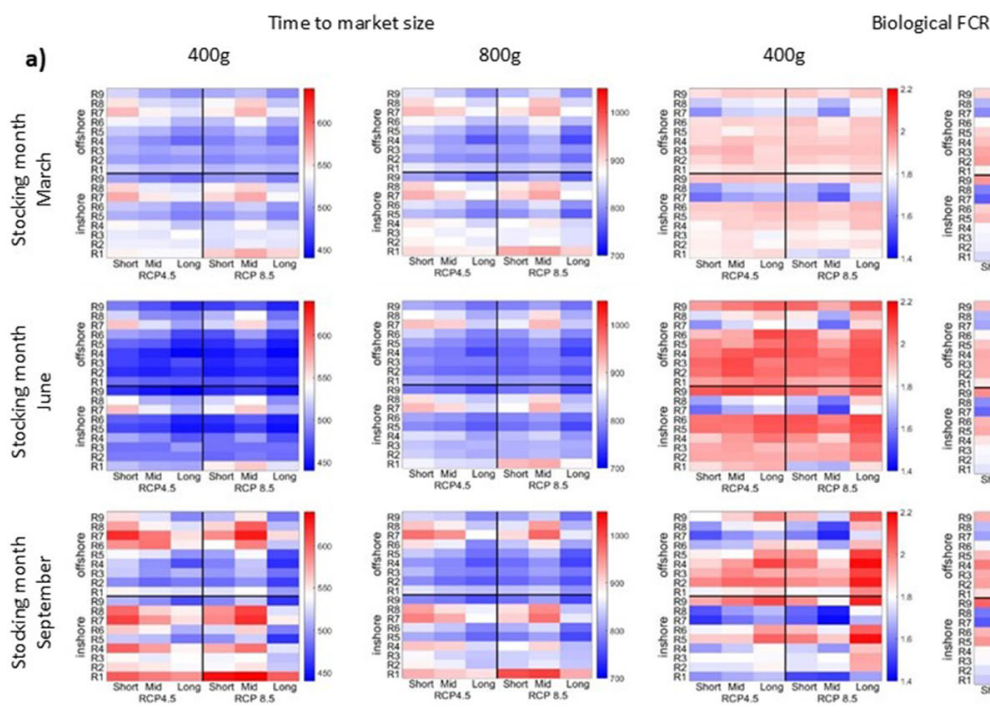

$800 \mathrm{~g}$


Fig. 2 Species: a European seabass, b meagre. Heat maps for time (days) to two market sizes and biological FCR for the nine regions (R1-R9), inshore and offshore locations, the three climate projections (short-, mid-, and longterm), and the two climate IPCC scenarios (RCP 4.5 and RCP 8.5). The rows represent the different stocking periods. Blue colours relate to small values and red to large values, while the average value among stocking months is given in white 
Figure 2 illustrates, for the various scenarios, the time to reach the common commercial sizes described in the previous section as well as the FCR in the form of heat maps.

In most regions, there seems to be a progressive decrease in the time to reach the market size when projecting forward in time (note the colour change of each line in each panel). This holds for both species and both market sizes. However, notable exceptions exist. For some regions, the production time exhibits a temporary increase in the mid-term before finally decreasing in the long term, a trend that can be explained by the temperature projections which posit negligible or even negative shifts in the mid-term (Fig. S4 in the ESM). That being said, all regions will exhibit a decrease in time to market size in the long-term future. Moreover, regarding the time to market size, regional differences appear with some regions exhibiting only small changes in the future (R3, R5) compared to others (R9). This is consistent across species, climate scenarios and market sizes, indicating a strong biological dependence to the environmental data (temperature and wind) forced into the simulations.

Furthermore, the relative changes in the time to market size ( $800 \mathrm{~g})$ are shown (Fig. 3) for both species under RCP8.5 which is the scenario with the most pronounced changes.

Negative values (blue) indicate a decrease in the time to market size compared to now, and positive values (red) indicate the opposite. Overall, the relative changes are small for both species and do not exceed $10 \%$. Particularly for the mid-term, and depending on the region, time to market size may increase by up to $9 \%$ for E. seabass and to a lesser extend for meagre (6\%) which will be less affected. This counter-intuitive trend can be predominantly attributed to the relatively low temperatures forecasted for some of the months in the mid-term (ESM, Fig. S4). On the other hand, the temperature increase projected for the long-term may lead to fish growing significantly faster by 2050 . The largest relative benefit will be registered for meagre which may reach commercial size $10 \%$ faster, while for E. seabass, it may speed up by $7 \%$. Although the relative change may be small, the absolute decrease in production days may be substantial as indicated by the supporting histograms (Fig. 3, right) ranging between 20 and 40 for meagre and 60 and 80 for E. seabass. Furthermore, the decrease in time to market size will be the largest for the September stocking comparatively to March and June as a consequence of the increased autumn temperatures. This observation holds for both species. Lastly, with respect to the inshore/offshore location
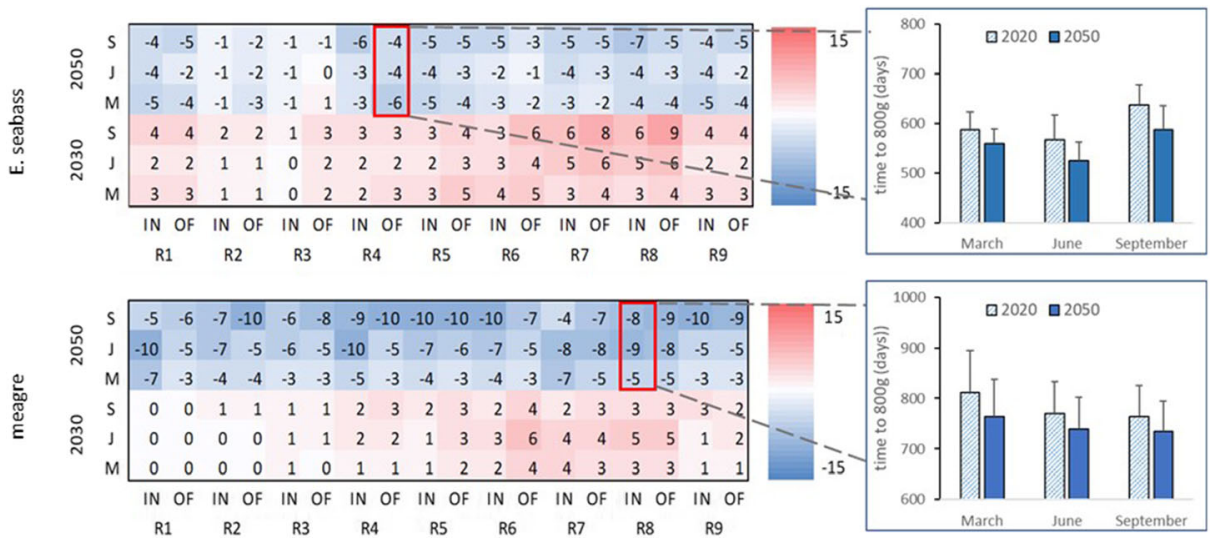

Fig. 3 Relative differences (\%) in time to market size (800 g) between short (2020)- and mid (2030)- and shortand long (2050)-term projections under RCP8.5 for E. seabass and meagre. The letters M, J, and S denote the stocking months March, June, and September, R1-R9 the regions, and IN-OF the inshore and offshore farms. Histograms show the absolute mean time to market size (days) for highlighted examples, including the simulated variability (standard deviation) 
of the farm, the effect seems to be highly region-specific. Differences are generally marginal and depending on the stocking month, some of the regions exhibit faster growth inshore compared to their offshore counterparts and vice versa.

In fact, while the isolated effect of managerial drivers such as the timing of stocking, the selected market size, and the inshore/offshore location as well the selection of region may range from small to considerable, their cumulative effect on time to market size is significant. In many cases, this effect may be as high as that of the climate-driven change as seen in Fig. 4.

For instance, the choice of region is among the most important. Differences between regions may be as high as $60-80$ days for E. seabass to reach $400 \mathrm{~g}$ and up to 80 days for meagre to reach $800 \mathrm{~g}$. In addition, even within the same region, the period of stocking has a significant effect with fish reaching the above sizes 80 days earlier for the June stocking compared to the September stocking as seen from regions R1 and R9. Furthermore, market size itself is a contributor to these differences. Depending on the targeted market size, it may be preferable to stock at different months to take advantage of the projected temperature shifts. For instance, while stocking in September is suboptimal for $400 \mathrm{~g}$ E. seabass, it becomes a viable option for $800 \mathrm{~g}$ fish, as seen clearly from regions R5 and R9 where the market size is reached at roughly the same time for all stocking months. Taking into account that the inshore/
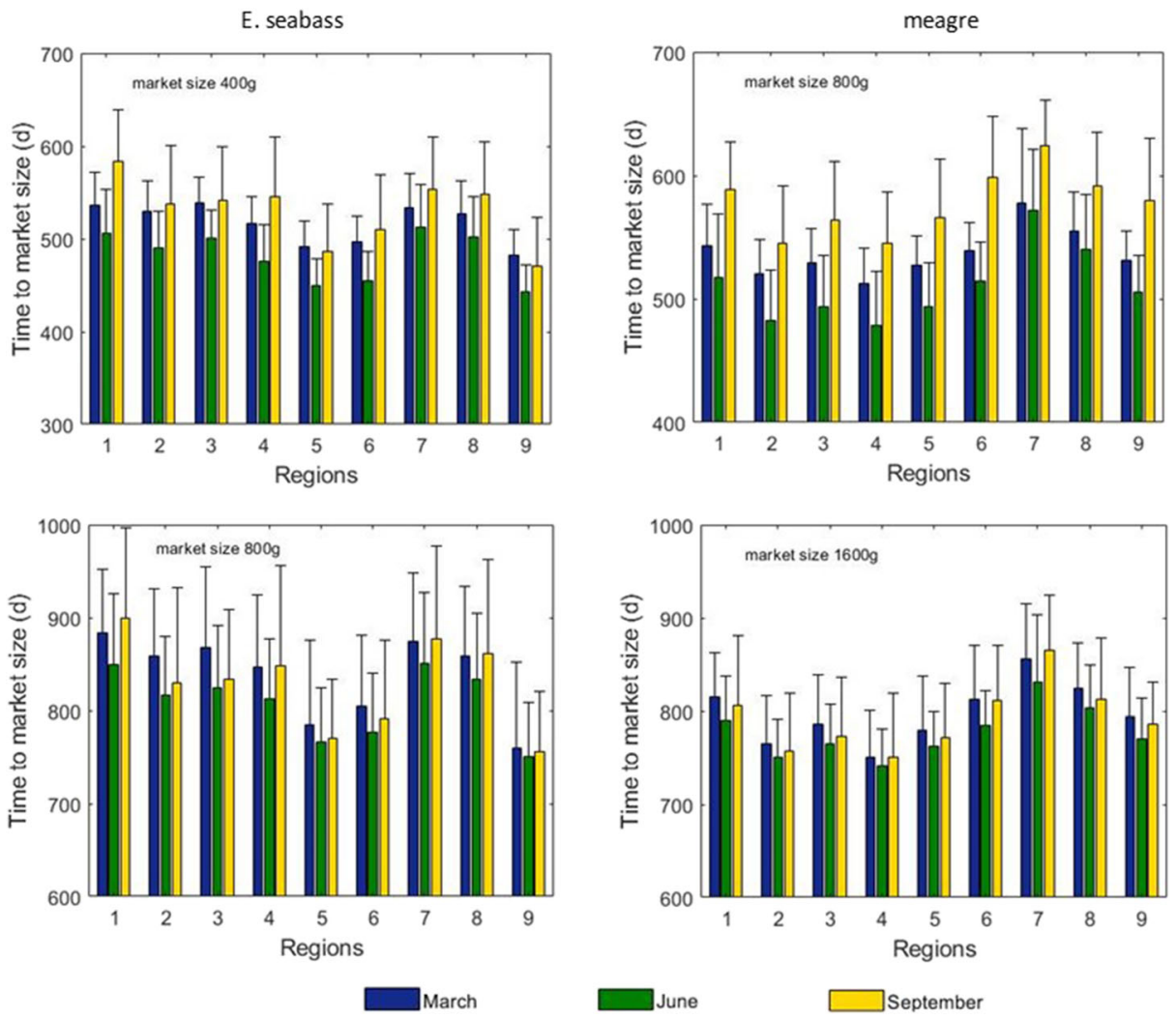

Fig. 4 Time to market size for the long-term climate projection of RCP 8.5 scenario for all regions (1-9). Left column: E. seabass at market size 400 and 800 g. Right column: meagre at market size 800 and 1600 g. Bars denote the simulated variability (standard deviation) 
offshore location of a farm may also contribute to small differences in growth, it becomes apparent that cumulatively, the various managerial drivers can have an effect on growth at least as large (> 80 days) as the one projected due to climate change (up to 80 days) (Figs. 3 and 4).

With respect to FCR, trends in the temporal and spatial changes are not as straightforward, yet some general patterns can be observed (Fig. 2). Contrary to the time to market size, the overall trend for FCR is to increase when projecting forward in time. The trend is more pronounced for RCP8.5 compared to RCP4.5, while significant regional differences exist. Regions like R1, R7, and R8 which are generally cold regions exhibit the lowest FCR values, and the temporal shifts are the smallest for these regions when projecting forward in time. In addition, independently of region and time period, FCR differs between inshore and offshore farms, with the lowest values generally being projected for the latter.

\subsection{Effects at the farm level}

This section analyses effects of extreme events that occur at the farm level in terms of biomass production and profitability under the production scenario (200,000 individuals, $800 \mathrm{~g}$ market size) described in the "Methods". This includes the simulation of the three extreme event scenarios, namely, the "mild extreme events" ( $1 \%$ mortality for heatwaves and storms), the "intense heatwaves" (5\% and 1\% mortality for heatwaves and storms, respectively), and the "intense storminess" (1\% and 5\% mortality for heatwaves and storms, respectively) scenarios.

The simulations suggest that under the considered scenarios, the time period $(2030,2050)$ and the location of the farm (inshore/offshore) are among the parameters with the highest impact on biomass production and, by extension, on profitability. For these parameters, the summarized findings for E. seabass are shown in Fig. 5, while we refer to the matrices in the
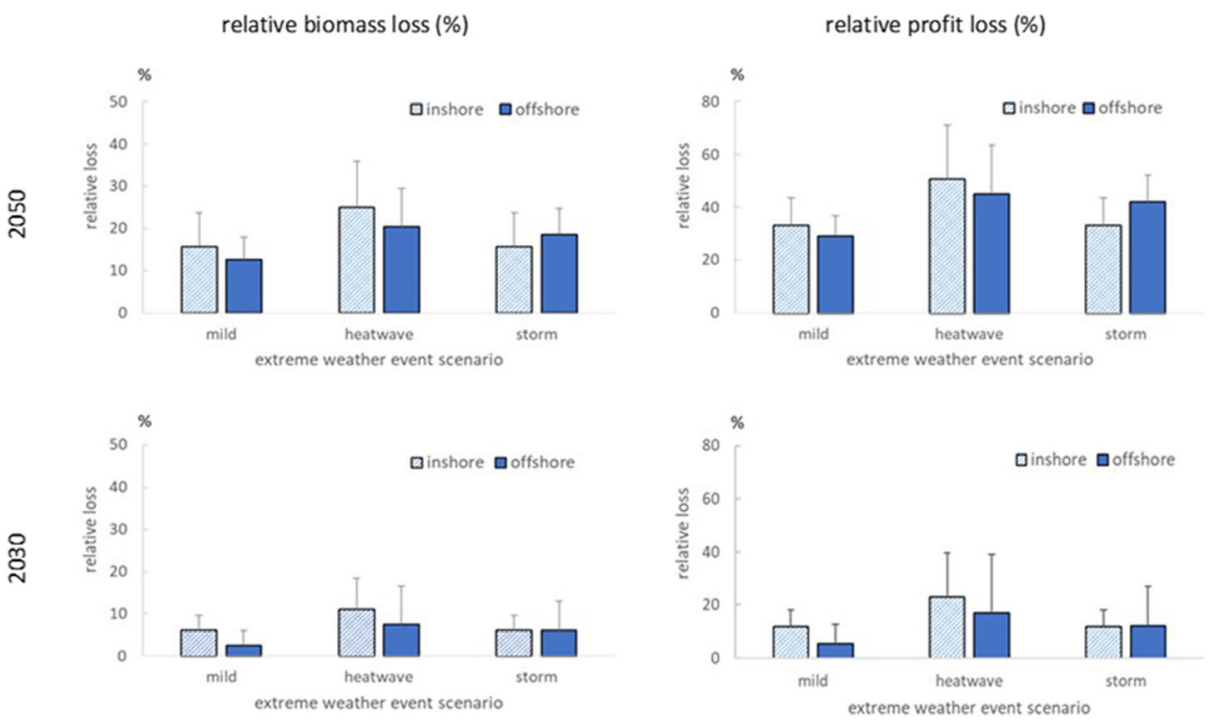

Fig. 5 Relative biomass (left) and profit (right) loss for E. seabass in 2030 and 2050 compared to the present (2020). Three extreme event scenarios (mild, increased heatwaves, increased storminess) are considered under RCP8.5 for a model farm that stocks 200,000 juveniles and harvests them once they reach the market size of $800 \mathrm{~g}$. The histograms represent the average across regions and stocking months, including the standard deviation 
ESM (Fig. S5) for the complete dataset which includes the simulated results further broken down by region and stocking month.

Considering the time period, the temporal scale appears to have the highest impact. Compared to the present, the effects on biomass and profitability will be small in the midterm but will double for the long-term projections. Initially, production volume will exhibit marginal losses in the order of $0-16 \%$. These may translate to moderate losses in profit, ranging between 1 and 25\%, which for some cases may reach alarming values up to $40 \%$. However, by 2050 , biomass production and profit will drastically deteriorate across all scenarios. Decrease in biomass will generally be in the range of $25-40 \%$ resulting in devastating effects for farm profitability. With average profit being half that of today's and cases with losses as high as $82 \%$, fish farming may become a financially unviable activity. These results are attributed to the increased frequency of extreme events in the long-term, and predominantly the heatwaves. While there may be differences due to the other considered factors, in most cases, the differences do not seem significant enough to salvage production.

With respect to the inshore/offshore location of the farm, significant patterns can be observed. Under the mild extreme even scenario, inshore farms exhibit higher losses than their offshore counterparts. This suggests that the observed losses are predominantly due to heatwaves which are more frequent in coastal areas rather than in offshore locations where the main type of extreme weather event is storms (see also Fig. S5 in the ESM). This pattern also holds for the increased heatwave scenario, although losses are generally higher than the mild scenario both inshore and offshore. Conversely, the simulations from the intense storminess scenario suggest the opposite trend with higher losses for the offshore sites and therefore provide insights into the potential challenges to be anticipated in an offshore environment. Overall, this scenario predicts moderate losses compared to the intense heatwave scenario. In fact, in their vast majority, inshore locations are not affected at all by increased storminess, and they exhibit the exact same values as in the mild extreme event scenario. This is a demonstration that although the wind velocity data forced into the simulations may have had an effect on feeding, they never exceeded the thresholds set for storm-induced mortality. On the contrary, there are notable changes on biomass and profit in the offshore farms, indicating a higher frequency of storm events in those areas. However, their frequency is lower than that of heatwaves as depicted by the overall low additive effects on the projected losses.

Interestingly, irrespective of the time period and for both inshore and offshore farms, there is some variability among simulations, and especially under the increased heatwave scenario. This suggests that the stocking month and the regional differences also contribute to differences in biomass production and profit. In fact, some regions are seemingly more resilient than others (see Fig. S5 in the ESM). For instance, region R1 which is the least afflicted region is also the northernmost region and is associated with low occurrence of heatwaves. Furthermore, the stocking month may also play a role under certain scenarios. For example, in the mild extreme event scenario, September seems to be the preferable stocking period, with biomass and profit losses being less than that of June and March. Presumably, this is due to the large time it takes E. seabass to reach $800 \mathrm{~g}$ (Fig. 2), which means that the March and June stocking will have to spend an additional summer at sea and therefore be subjected to more heatwaves.

Finally, the results for meagre exhibit similar patterns (ESM, Fig. 5). Alarming biomass and profit losses are predicted by year 2050, while some potential is seen for offshore locations, where farms will register fewer losses. The main difference is that the effects on meagre are less pronounced, presumably due to the fast growth of meagre which does not require a second winter or summer at sea to reach the targeted size and therefore is subjected to fewer extreme weather events. 


\section{Discussion}

In this work, a farm level approach was employed to investigate potential effects of climate change on a subset of Mediterranean aquaculture. The general trend stemming from our simulations is that at the individual level, fish may benefit from warmer temperatures in the future in terms of growth, thus reaching commercial sizes faster. While the relative differences between now and the future will generally be small, such benefits may translate to significant reductions in the number of production days needed to reach common market sizes. However, growth benefits will be largely offset by the adverse effects of extreme weather events at the population level. Such events will be more frequent in the future, and depending on the intensity one assigns to them, they could cause losses in biomass and farm profits that may range from mild to detrimental for the industry.

A comprehensive assessment of climate change threats requires the consideration of all the related climate drivers and their potential effects. As described in the introduction, explicit modelling of such effects may be possible only for a handful of drivers, and even in those cases, the robustness of the forecasting is heavily reliant on the availability and quality of data. While temperature is undeniably the most important environmental driver and significant effort should be given in decreasing the associated uncertainties and improving the reliability of the projections, it is vital that other drivers such as acidification, HABs, diseases, salinity, and oxygen limitations are also considered. Admittedly, some of these drivers such as salinity and $\mathrm{pH}$ have little relevance for marine cage farming, with literature regarding the latter suggesting that adult fish are able to withstand the projected $\mathrm{CO}_{2}$ concentrations in the near future for the Mediterranean (LacoueLabarthe et al. 2016). At the same time, it is challenging to incorporate the effects of other drivers such as HABs and oxygen limitations due to low data availability. In this work, effort was given in including extreme weather events indirectly by assuming an effect on feeding and mortality. Although the approach relied on selecting relatively arbitrary thresholds and therefore does not reflect precise modelling, it offered means of investigating effects of storminess and heatwaves which are both critical for the industry (Jensen et al. 2010; Le et al. 2020). The simulations suggest that while storm events will occur predominantly in offshore locations, both inshore and offshore locations will be eventually afflicted by heatwaves in the long-run as temperatures continue to rise, which is in line with the current understanding of heatwaves and their consequences for aquatic life (Bacheler et al. 2019; Oliver et al. 2018). Indeed, our results indicate that depending on the severity one assigns to those drivers, the effects can vary from insignificant to devastating for production and thus farm viability. In fact, their impact can be severe enough to overshadow the effects of all other environmental and managerial drivers which further stresses the need to view climate change holistically and not only as the result of rising temperatures. The presented approach is of course by no means exhaustive, and future climate work should give emphasis in generating the necessary climate and biological data to bridge some of the existing knowledge gaps and also on including effects of additional drivers into modelling.

It is important to highlight that the simulations presented here assume no technological advances for the industry or genetic improvement for the farmed species which is evidently not the case. Similarly, no assumptions are made for shifts in the targeted species. For instance, as seen from our simulations, fast growing fish such as meagre may be advantageous to farm, especially under specific stocking months. Therefore, other candidate species for the diversification of 
Mediterranean aquaculture such as the greater amberjack, which have fast growing and temperature resilience characteristics, may also become better for farming in the future. Generally, advancements in the sector happen at a fast pace (Føre et al. 2018), and it is possible that the industry will adapt to the projected threats long before they occur, provided that the threats are identified and appropriate actions are taken. In fact, our work may point to potential measures that can facilitate adaptation to climate change.

One such measure relates to offshore farming. The significance of offshore farming for the further expansion of aquaculture has been highlighted (Soto and Wurmann 2019), and our simulations suggest that it also offers some potential for adaptation to climate change (Klinger et al. 2017). It was shown that while storm events will occur mostly in offshore locations, their impact will not be as severe as that of heatwaves which will occur at higher frequencies at inshore locations. Particularly for species like meagre, with a fast production cycle, it appears that the adverse effects of heatwaves are largely mitigated at offshore sites. Secondly, simulations suggest that adjustments in the stocking strategies may be adaptive to climate change. For instance, the established practice for E. seabass and meagre currently is to transfer fish to marine cages during spring or summer. However, our results suggest that September may become a preferable month for some scenarios and certain market sizes. Finally, some differences in FCR were observed depending on region, farm location, and time scale, which could provide useful information for developing marketing plans. The optimum combination of time to market size and FCR is subjective and depends on each farm's production strategy (e.g. high demand for fish at specific size or period of the year may justify a larger FCR if the revenue of producing fish faster is sufficient). Therefore, while our results cannot provide recommendations for an optimum stocking scenario nor a preferable stocking month, the information presented here may be used to tailor one's production according to specific production goals and strategies in the future.

Within the ClimeFish project, an interactive decision support system (DSS) was developed that offers aquaculture stakeholders the chance to further experiment with the results presented here (Stavrakidis-Zachou et al. 2019b; Stavrakidis-Zachou et al., submitted). The software is freely available and provides visualization of biological and economic results for climate, husbandry, and socioeconomic scenarios that the users can construct, test, and compare (https://zenodo.org/record/3627546\#. XonXUXJS82w). It also allows to specify the severity (via assigning different mortalities or costs) for the extreme weather events according to one's own perception which further increases the possibilities that can be explored as opposed to the few selected examples presented here. Overall, these DSS features may be used as supporting information to the forecasting results discussed here, thus contributing to attaining a better understanding of the range of future possibilities and in turn aiding the responsible management of the industry for the years to come.

Adapting to climate change is challenging. It requires joint efforts from academia, administration, and industry, while a fundamental step in this process is the extensive evaluation of potential effects which is often hindered by significant knowledge gaps. Here, we offer a science-based evaluation for some of the potential effects based on the available knowledge 
and data and by adopting a modelling framework that uses a model farm approach. Our results provide quantification of potential threats for an aquaculture sector representative to the Mediterranean Sea while suggesting possibilities to benefit from emerging opportunities. This work advances knowledge building regarding climate change effects on a vulnerable aquaculture area and may contribute to the sector's readiness for tackling important challenges in the decades to come.

Supplementary Information The online version contains supplementary material available at https://oi.org/ 10.1007/s10584-021-03096-y.

Funding This work was supported by the European Union Horizon 2020 Project ClimeFish (677039).

Availability of data and material The simulation data are open access and available at Zenodo (https://zenodo. org/record/3564309\#.X47Psu1S82w), version: https://doi.org/10.5281/zenodo.3564309.

\section{Declarations}

Conflict of interest The authors declare no competing interests.

Open Access This article is licensed under a Creative Commons Attribution 4.0 International License, which permits use, sharing, adaptation, distribution and reproduction in any medium or format, as long as you give appropriate credit to the original author(s) and the source, provide a link to the Creative Commons licence, and indicate if changes were made. The images or other third party material in this article are included in the article's Creative Commons licence, unless indicated otherwise in a credit line to the material. If material is not included in the article's Creative Commons licence and your intended use is not permitted by statutory regulation or exceeds the permitted use, you will need to obtain permission directly from the copyright holder. To view a copy of this licence, visit http://creativecommons.org/licenses/by/4.0/.

\section{References}

Azzurro E, Sbragaglia V, Cerri J, Bariche M, Bolognini L, Souissi JB, Modschella P (2019) Climate change, biological invasions, and the shifting distribution of Mediterranean fishes: A large-scale survey based on local ecological knowledge. Glob Chang Biol 00:1-14. https://doi.org/10.1111/gcb.14670

Bacheler NM, Shertzer KW, Cheshire R, MacMahan JH (2019) Tropical storms influence the movement behavior of a demersal oceanic fish species. Sci Rep 9:1481

Besson M, Vandeputte M, van Arendonk JAM, Aubin J, de Boer IJM, Quillet E, Komen H (2016) Influence of water temperature on the economic value of growth rate in fish farming: The case of sea bass (Dicentrarchus labrax) cage farming in the Mediterranean. Aquaculture 462:47-55

Brugère C, De Young C (2015) Assessing climate change vulnerability in fisheries and aquaculture. Available methodologies and their relevance for the sector. FAO Fisheries and Aquaculture Technical Paper No. 597. Rome, FAO

Claireaux G, Couturier C, Groison AL (2006) Effect of temperature on maximum swimming speed and cost of transport in juvenile European sea bass (Dicentrarchus labrax). J Exp Biol 209:3420-3428

Cobo A, Llorente I, Luna L, Luna M (2019) A decision support system for fish farming using particle swarm optimization. Comput Electron Agric 161:121-130. https://doi.org/10.1016/j.compag.2018.03.036

Collins C, Bresnan E, Brown L, Falconer L, Guilder J, Jones L, Kennerley A, Malham S, Murray A, Stanley M (2020) Impacts of climate change on aquaculture. In: MCCIP science review 2020. Marine Climate Change Impacts Partnership, Lowestoft, pp 482-520 
Crozier LG, Hendry AP (2013) Plastic and evolutionary responses to climate change in fish. Evol Appl 7:68-87

Falconer L, Hjollo S, Telfer T, McAdam B, Hermansen O, Ytteborg E (2019) The importance of calibrating climate change projections to local conditions at aquaculture sites. Aquaculture 514:734487. https://doi.org/ 10.1016/j.aquaculture.2019.734487

Fankhauser S (2017) Adaptation to climate change. Ann Rev Resour Econ 9:209-230. https://doi.org/10.1146/ annurev-resource-100516-033554

FEAP (2016) European aquaculture production report 2007-2015. Federation of European Aquaculture Producers. Prepared by the FEAP Secretariat

FEAP (2017) European aquaculture production report 2008-2016. Federation of European Aquaculture Producers. http://feap.info/index.php/data/. Accessed September 30, 2020

FGM (2019) Aquaculture in Greece, 2019. Annual report. Federation of Greece Maricultures

Føre M, Frank K, Norton T, Svendsen E, Alfredsen JA, Dempster T, Eguiraun H, Watson W, Stahl A, Sunde LM, Schellewald C, Skøien K, Alver MO, Berckmans D (2018) Precision fish farming: a new framework to improve production in aquaculture. Biosyst Eng 173:176-193

Francisco S, Pimentel MS, Paula JR, Rosa I, Madeira V, Repolho T, Marques A, Rosa R (2015) Combined effects of climate change and methylmercury exposure on marine fish ecophysiology. Third International Symposium on Effects of Climate Change on the World's Oceans, Santos City, pp 23-27

Hawkins E, Osborne TM, Ho CK, Challinor AJ (2013) Calibration and bias correction of climate projections for crop modelling: An idealised case study over Europe. Agric For Meteorol 170:19-31

IPCC (2013) Climate change 2013: The physical science basis. Working group I contribution to the fifth assessment report of the intergovernmental panel on climate change. Cambridge University Press, Cambridge

Islam MJ, Slater MJ, Bögner M (2020) Extreme ambient temperature effects in European seabass, Dicentrarchus labrax: Growth performance and hemato-biochemical parameters. Aquaculture 522:735093. https://doi.org/ 10.1016/j.aquaculture.2020.735093

Jackson D, Drumm A, McEvoy S, Jensen Ø, Mendiola D, Gabiña G, Borg JA, Papageorgiou N, Karakassis Y, Black KD (2015) A pan-European valuation of the extent, causes and cost of escape events from sea cage fish farming. Aquaculture 436:21-26

Jensen Ø, Dempster T, Thorstad EB, Uglem I, Fredheim A (2010) Escapes of fishes from Norwegian sea-cage aquaculture: Causes, consequences, and prevention. Aquac Environ Interact 1:71-83

Kir M, Sunar MC, Altindag BC (2017) Thermal tolerance and preferred temperature range of juvenile meagre acclimated to four temperatures. J Therm Biol 65:125-129

Klinger DH, Levin SA, Watson JR (2017) The growth of finfish in global open-ocean aquaculture under climate change. Proc R Soc B Biol Sci 284:20170834. https://doi.org/10.1098/rspb.2017.0834

Kooijman SALM (2010) Dynamic energy budget theory for metabolic organisation. Cambridge University Press, Cambridge

Lacoue-Labarthe T, Nunes PAL, Ziveri P, Cinar M, Gazeau F, Hall-Spencer J, Hilmi N, Moschella P, Safa A, Sauzade D, Turley C (2016) Impacts of ocean acidification in a warming Mediterranean Sea: An overview. Reg Stud Mar Sci 5:1-11

Le MH, Dinh KV, Nguyen MV, Ronnestad I (2020) Combined effects of a simulated marine heatwave and an algal toxin on a tropical marine aquaculture fish cobia (Rachycentron canadum). Aquac Res 51:2525-2544

Lotze HK, Tittensor DP, Bryndum-Buchholz A, Eddy TD, Cheung WW, Galbraith ED, Bopp L (2018) Ensemble projections of global ocean animal biomass with climate change. bioRxiv 2018:467175. https:// doi.org/10.1101/467175

Marques GM, Lika K, Augustine S, Pecquerie L, Kooijman SALM (2019) Fitting multiple models to multiple data sets. J Sea Res 143:48-56

Monaco CJ, McQuaid CD (2018) Applicability of dynamic energy budget (DEB) models across steep environmental gradients. Sci Rep 8:16384. https://doi.org/10.1038/s41598-018-34786-w

Oliver EC, Donat MG, Burrows MT, Moore PJ, Smale DA, Alexander LV, Benthuysen JA, Feng M, Gupta AS, Hobday AJ (2018) Longer and more frequent marine heatwaves over the past century. Nat Commun 9:1324. https://doi.org/10.1038/s41467-018-03732-9

Ozolina K, Shiels HA, Olivier H, Claireaux G (2016) Intraspeceific individual variation of temperature tolerance associated with oxygen demand in the European sea bass (Dicentrarchus labrax). Conserv Physiol 8:cov060

Pérez-Jiménez A, Peres H, Rubio VC, Oliva-Teles A (2012) The effect of hypoxia on intermediary metabolism and oxidative status in gilthead sea bream (Sparus aurata) fed on diets supplemented with methionine and white tea. Comp Biochem Physiol C 155:506-516

Pope EC, Ellis RP, Scolamacchia M, Scolding JWS, Keay A, Chingombe P, Shields RJ, Wilcor R, Speirs DC, Wilson RW, Lewis C, Flynn KJ (2014) European sea bass, Dicentrarchus labrax, in a changing ocean. Biogeosciences 11:2519-2530 
Reid GK, Gurney-Smith H, Flaherty M, Garber A, Forster I, Brewer-Dalton K, Knowler D, David M, Chopin T, Rich M, Caitlin S, Sena S (2019) Climate change and aquaculture: Considering adaptation potential. Aquac Environ Interact 11:603-624

Rosa R, Marques A, Nunes ML (2012) Impact of climate change in Mediterranean aquaculture. Rev Aquac 4: 163-177

Samaras A, Espírito Santo C, Papandroulakis N, Mitrizakis N, Pavlidis M, Höglund E, Pelgrim T, Zethof J, Spanings T, Vindas M, Ebbesson L, Flik G, Gorissen M (2018) Allostatic load and stress physiology in European seabass (Dicentrarchus labrax L.) and gilthead seabream (Sparus aurata L.). Front Endocrinol 9: 451. https://doi.org/10.3389/fendo.2018.00451

Sarà G, Gouhier TC, Brigolin D, Porporato EM, Mangano MC, Mirto S, Mazzola A, Pastres R (2018) Predicting shifting sustainability trade-offs in marine finfish aquaculture under climate change. Glob Chang Biol 24: $3654-3665$

Soto D, Wurmann C (2019) Offshore aquaculture: A needed new frontier for farmed fish at aea. In: In: The future of ocean governance and capacity development. Brill Nijhoff, Leiden, pp 379-384

Spatharis S, Dolapsakis NP, Economou-Amilli A, Tsirtsis G, Danielidis DB (2009) Spatial and temporal dynamics of potentially harmful microalgae in a confined Mediterranean ecosystem. 9th Panhellenic Symposium on Oceanography and Fisheries, Patras, pp 13-16

Stavrakidis-Zachou O, Papandroulakis N, Lika K (2019a) A DEB model for European sea bass (Dicentrarchus labrax): Parameterisation and application in aquaculture. J Sea Res 143:262-271

Stavrakidis-Zachou O, Papandroulakis N, Sturm A, Anastasiadis P, Wätzold F, Lika K (2019b) Towards a computer-based decision support system for aquaculture stakeholders in Greece in the context of climate change. Int J Sustain Agric Manag Inform 4:219-234

Talbot SE, Widdicombe S, Hauton C, Bruggeman J (2019) Adapting the dynamic energy budget (DEB) approach to include non-continuous growth (moulting) and provide better predictions of biological performance in crustaceans. ICES J Mar Sci 76:192-205. https://doi.org/10.1093/icesjms/fsy164

Teske S (2019) Achieving the Paris climate agreement goals. Springer, Cham

Van Vuuren DP, Riahi K, Moss R, Thomson A, Nakićenović N, Edmonds JM, Kram T, Berkhout F, Swart R, Janetos A (2011) The representative concentration pathways: An overview. Clim Chang 109:5-31

Wells ML, Trainer VL, Smayda TJ, Karlson BSO, Trick CG, Kudela RM, Ishikaqa A, Bernard S, Wulff A, Anderson DM, Cochlan WP (2015) Harmful algal blooms and climate change: Learning from the past and present to forecast the future. Harmful Algae 49:68-93

Yang Y, Ramezani R, Bouwer Utne I, Mosleh A, Lader PF (2020) Operational limits for aquaculture operations from a risk and safety perspective. Reliab Eng Syst Saf 204:107208. https://doi.org/10.1016/j.ress.2020. 107208

Publisher's note Springer Nature remains neutral with regard to jurisdictional claims in published maps and institutional affiliations. 